\title{
Há desindustrialização no Brasil? Um estudo da abordagem clássica e de análises alternativas entre 1998 e 2014 * Bento Antunes de Andrade Maia ${ }^{* *, * * *}$
}

\begin{abstract}
Resumo
Há uma grande controvérsia na literatura econômica brasileira a respeito da hipótese de desindustrialização do Brasil. Os diferentes diagnósticos se devem às distintas definições do processo e aos critérios de análise. O presente estudo irá abordar o tema tanto a partir da definição clássica, utilizada no trabalho seminal de Rowthorn e Wells (1987), como por três conceitos alternativos: i) a desindustrialização prematura; ii) a "visão de Cambridge" e iii) a Mudança Estrutural no interior da indústria de transformação. Os resultados analisados mostram que a desindustrialização brasileira é mais intensa quando analisada pelas abordagens alternativas, pois esse processo ocorre em um nível de produtividade agregado inferior à desindustrialização dos países avançados, a estrutura produtiva da indústria de transformação está se especializando regressivamente, ampliando sua participação em setores de menor produtividade e tem apresentado saldo comercial deficitário a partir de 2008.
\end{abstract}

Palavras-chave: Desindustrialização; Especialização regressiva; Mudança estrutural.

\begin{abstract}
Is Brazil desindustrializing? A study of the classical approach and alternative analyses between 1998 and 2014

There is great controversy in the Brazilian economic literature regarding the hypothesis of Brazilian deindustrialization. The different diagnoses are due to the different definitions of the process and the analysis criteria. The present study will address the theme both from the classical definition used in the seminal work of Rowthorn and Wells (1987) and according to three alternative concepts: i) premature deindustrialization; ii) the "Cambridge vision" and iii) structural change within the manufacturing industry. The results show that Brazilian deindustrialization is more intense when analyzed considering the alternative approaches, since this process occurs at a lower level of aggregate productivity than the deindustrialization in advanced countries, the productive structure of the manufacturing sector is increasing its participation in low productivity sectors and has presented a deficit trade balance since 2008 .
\end{abstract}

Keywords: De-industrialization; Structural change; Industrial specialization.

JEL O14, O33, O47.

\section{Introdução}

O fenômeno da desindustrialização foi analisado, primeiramente, pela decomposição da economia entre os seus três macro-setores - agricultura, indústria e o de serviços - e a perda de participação relativa do setor industrial. A agricultura, antigamente o setor dominante foi

\footnotetext{
* Artigo recebido em 22 de janeiro de 2018 e aprovado em 18 de fevereiro de 2019.

${ }^{* *}$ Professor da Faculdades de Campinas (Facamp), Campinas, SP, Brasil. E-mail: bentoaam@gmail.com. ORCID: https://orcid.org/0000-0002-3765-5823.

${ }^{* * *}$ Economista do Centro de Cidadania Fiscal (CCiF), São Paulo, SP, Brasil.
} 
perdendo participação para o setor secundário devido ao processo de industrialização após a Revolução Industrial (1820-1870). Posteriormente, a partir das décadas de 1960, 1970, passouse a observar, nos países de industrialização madura, que o setor de serviços ultrapassou a relevância do setor secundário, o que ficou conhecido na literatura como processo de desindustrialização' ${ }^{1}$ (Rodrik, 2016; Kruger, 2008).

Os dois principais indicadores para medir essa transformação na estrutura produtiva são: a participação do valor adicionado da Manufatura no PIB e a participação do emprego industrial sobre o total de empregos na economia ${ }^{2}$. No entanto, a análise a respeito do processo de desindustrialização ganhou diversas contribuições teóricas ao longo dos anos, o que aprofundou e tornou mais complexo o seu estudo e entendimento. Além da abordagem original sobre a desindustrialização que investiga somente a participação da manufatura no total de empregos da economia ou no total do PIB, outras definições se desenvolveram. Ademais, as causas da desindustrialização são diversas e se alteram de acordo com o grau de desenvolvimento de cada país com o contexto mundial, circunstâncias internas do país e do período de análise.

O Brasil não é exceção e a questão da desindustrialização no país é permeada por diferentes interpretações do fenômeno, sem um claro diagnóstico de como a própria desindustrialização está sendo interpretada ou do porque os seus resultados não são compatíveis com o de seus pares. Por isso, é fundamental realizar uma análise da desindustrialização no Brasil deixando patente a concepção que se tem acerca dessa Mudança Estrutural.

O principal objetivo deste estudo é segmentar e analisar a desindustrialização tanto pela ótica clássica, como por suas principais abordagens alternativas ${ }^{3}$ entre 1998 e 2014. Dessa forma, será investigada a hipótese de desindustrialização no Brasil a partir da i) análise intersetorial - a abordagem tradicional -, ii) comparativamente com o desenvolvimento de outros países (desindustrialização prematura), iii) pela análise da Balança Comercial de manufaturas (visão de Cambridge) e iv) intra-setorialmente, a Mudança Estrutural no interior da indústria de transformação.

Assim, o presente artigo contribui para a literatura acadêmica, pois: i) realiza uma revisão da literatura sobre a desindustrialização, explicitando suas definições, conceitos e interpretações para o Brasil; ii) segmenta a análise da desindustrialização de modo a separar a abordagem clássica, convencional, de interpretações mais específicas, alternativas, mas que

(1) De acordo com Rowthorn e Ramaswamy (1999) e Palma (2014), as economias avançadas tiveram sua participação do emprego industrial reduzida de $28 \%$ para $18 \%$ entre 1970 e 1994 e perderam cerca de 25 milhões de empregados na manufatura.

(2) "There is a variety of industrialization/deindustrialization measures in the literature. Some studies focus on manufacturing employment (as a share of total employment), while others use manufacturing output (MVA as a share of GDP)" (Rodrik, 2016, p. 5).

(3) Denominaremos como alternativas, uma vez que diferem da definição clássica. 
Há desindustrialização no Brasil? Um estudo da abordagem clássica e de análises alternativas entre 1998 e 2014

são relevantes no debate e aprofundamento do assunto; e iii) evidencia que a desindustrialização brasileira é mais acentuada e preocupante a partir das análises alternativas.

A estrutura adotada no artigo para analisar o processo de desindustrialização no Brasil entre 1998 e 2014 está dividida em três partes. A primeira é focada na revisão teórica, demonstrando as diferentes definições sobre a desindustrialização, as suas principais causas e o debate acadêmico sobre a desindustrialização no Brasil. Já o segundo item descreve a metodologia utilizada, com destaque para a fonte dos dados e o método de shift-share; e o terceiro corresponde à análise da desindustrialização no Brasil de acordo com cada uma das definições sobre desindustrialização.

\section{Revisão teórica}

\subsection{Definições sobre a desindustrialização}

\subsubsection{Clássica}

A taxonomia clássica de desindustrialização foi formulada por Rowthorn e Wells (1987) que elencaram dois tipos possíveis de desindustrialização: i) a positiva, ou natural, que seria conjugada com rápido crescimento econômico e pleno emprego e ii) a negativa, na qual o valor adicionado e os empregos industriais se estagnam ${ }^{4}$.

\subsubsection{Positiva ou natural}

A desindustrialização positiva seria decorrência da própria evolução do tecido industrial de um país, que alcança um limite máximo de ocupação de mão de obra - em termos de participação do emprego total - e passa a declinar como decorrência natural da elevação da produtividade do setor manufatureiro devido aos ganhos tecnológicos e de escala. O setor de serviços, por sua vez, demanda parcelas cada vez maiores de trabalhadores, pois sua elasticidade da demanda por fator trabalhado é maior do que à da manufatura (Rowthorn; Wells, 1987).

Para Tregenna (2016), quando uma nação alcança determinado estágio de desenvolvimento, isto é, alta produtividade industrial, elevado nível tecnológico e um elevado nível de renda per capita ${ }^{5}$, ocorre uma redução no nível de empregos manufatureiros ${ }^{6}$. Ou seja, há uma correlação entre o nível de emprego industrial e a renda per capita, no qual os países de industrialização madura passaram a trocar empregos da manufatura por serviços especializados, como um corolário do seu desenvolvimento. Segundo Palma (2014): “As such, de-industrialisation could well have positive long-term growth effects".

(4) Os autores advertem que casos intermediários também são possíveis.

(5) De acordo com Rowthorn (1994; dados de 1990), essa queda se inicia em U\$12,000" (apud Palma, 2014, p. 10).

(6) De acordo com Rowthorn e Rawasmamy (1999) e Palma (2014), as economias avançadas tiveram sua participação do emprego industrial reduzida de $28 \%$ para $18 \%$ entre 1970 e 1994 e perderam cerca de 25 milhões de empregados na manufatura. 


\subsubsection{Negativa}

De acordo com Alderson (1999, p. 706), a desindustrialização negativa é o resultado de um desequilíbrio estrutural da economia que evita uma nação de alcançar o seu PIB potencial $^{7}$ e que se manifesta no declínio da produção industrial e na sua produtividade.

Uma nação pode enfrentar uma recessão em que tanto a renda real, como a produção manufatureira se estagnam, associadas com taxas crescentes de desemprego, em que a parcela de trabalho anteriormente empregada na indústria não consegue ser absorvida no setor terciário (Rowthorn e Wells, 1987).

Rowthorn e Wells (1987) argumentam que estes dois exemplos - desindustrialização negativa ou positiva - são duas situações extremas e que outros tipos de desindustrializações são possíveis, marcada por combinações intermediárias entre os dois casos opostos.

\subsection{Conceitos alternativos}

\subsubsection{Desindustrialização prematura}

A desindustrialização prematura $^{8}$, ou precoce, ocorre quando um país inicia sua retração da participação da indústria na economia com um nível de renda per capita substancialmente inferior aos dos países desenvolvidos. "These developing countries are turning into service economies without having gone through a proper experience of industrialization" (Rodrik, 2016, p. 3).

A desindustrialização prematura atinge as nações em desenvolvimento que passaram a se desindustrializar em um nível de renda per capita bastante inferior vis-à-vis as nações mais avançadas: "One way of thinking of premature deindustrialisation is as deindustrialisation that begins at a lower level of GDP per capita and/or at a lower level of manufacturing as a share of total" (Tregenna, 2016, p. 10).

De certa forma, a desindustrialização prematura é um caso de desindustrialização negativa, só que de modo não extremo como definiram Rowthorn e Wells (1987). Para Nassif et al. (2017, p. 6):

Premature deindustrialisation may occur when developing economies-which might have a rather diversified industrial base but have not yet completed their industrialisation process-are exposed to external competition without internal defence mechanisms of economic policy to continue the implementation of their structural change.

Segundo Rodrik (2016), a desindustrialização prematura remove o principal canal de crescimento acelerado que ocorreu no passado e diminui as possibilidades de as economias subdesenvolvidas convergirem para o padrão de renda das nações avançadas. Para o autor, as

(7) Aquele que utiliza todos os recursos produtivos sem gerar expansão da inflação.

(8) De acordo com a Unctad (2017), o termo desindustrialização prematura foi inicialmente empregado no estudo da Unctad (2003) e que desde então, vários autores têm demonstrado que o processo de redução da participação do valor adicionado da manufatura no PIB tem se iniciado em níveis de PIB per capita inferiores do que ocorria no passado. 
Há desindustrialização no Brasil? Um estudo da abordagem clássica e de análises alternativas entre 1998 e 2014

economias centrais do capitalismo estão se desindustrializando desde a década de 1970 e grande parte dos países subdesenvolvidos está em processo de desindustrialização antes mesmo de ter um tecido industrial de alta produtividade.

\subsubsection{Visão de Cambridge}

Outra interpretação da desindustrialização ficou conhecida como "Visão de Cambridge". Para essa vertente, a desindustrialização seria reflexo de um setor industrial incapaz de suprir a demanda nacional e pagar as necessidades de importações do país, ou seja, um setor manufatureiro deficitário comercialmente e que engendre restrições externas ao desenvolvimento econômico da nação. Dessa forma, o principal indicador para diagnosticar o processo de desindustrialização é a evolução do saldo comercial da indústria de transformação.

Segundo a visão de Cambridge, a desindustrialização representa um estado patológico que impede a economia de alcançar o seu pleno potencial de desenvolvimento, como destacam Dasgupta e Singh (2006, p. 19).

In a seminal contribution, Cairncross (1979) suggested that the best conceptualization of deindustrialization is what he called the 'Cambridge View', which he identified with that of Singh (1977). This argued that deindustrialization represents a pathological state when it stops the economy from being able to achieve its full potential of growth, employment, and resource utilization. The Cambridge analysis had been developed in relationship to the weaknesses of British manufacturing in the 1970s and 1980s, but it has current application to the advanced developing world.

Por esse critério, a desindustrialização não seria uma tendência natural da manufatura, seja do emprego ou do valor adicionado, pois ela é resultado das interações comerciais com o resto do mundo (Singh, 1977).

No Brasil, essa visão possui importantes reflexos na vertente Novo Desenvolvimentista ${ }^{9}$, com destaque para os trabalhos de Bresser-Pereira (Bresser-Pereira, 2008; Marconi e Rocha, 2012; Bresser-Pereira e Gala, 2010; Bresser-Pereira et al., 2015; Nassif et al., 2017).

\subsubsection{Mudança estrutural (falling behind)}

Bluestone e Harrison (1982) qualificaram a desindustrialização como um desinvestimento sistemático dos principais setores da indústria de transformação. Portanto, para esses autores, a desindustrialização não seria baseada em uma análise inter-setorial; seria causada pela especialização da produção de manufaturas em atividades menos sofisticadas.

Significado este, próximo ao de Rasiah (2011), que descreve a desindustrialização como o resultado de uma alteração da estrutura produtiva marcada por uma especialização

(9) Para maiores informações ver (Bresser-Pereira; Gala, 2010). 
regressiva em setores de menor produtividade e agregação de valor na composição do valor adicionado do setor industrial. De acordo com o autor:

Negative deindustrialization is not only associated with a stagnation or fall in value-added output and productivity, but is also characterized by a lack of structural shift from low value-added labour-intensive to high value added capital- and knowledge-intensive industries in manufacturing (Rasiah, 2011, p. 718).

Para Tregenna (2016), é preciso diagnosticar não apenas que um país está se desindustrializando inter-setorialmente, mas ir além e apontar quais são os setores que estão encolhendo. Isso porque o setor industrial não é homogêneo; co-existem setores manufatureiros de alta tecnologia, produtividade, encadeamentos produtivos, altos salários e nível de educação dos trabalhadores, com atividades industriais de baixa produtividade, salários e nível tecnológico, além de apresentar pequena capacidade de impulsionar outros setores devido a efeitos dinâmicos de encadeamento (Hirschman, 1958; Kaldor, 1966).

A desindustrialização analisada pela especialização da estrutura manufatureira em setores de menor produtividade é o padrão de desenvolvimento econômico oposto ao almejado pela tradição estruturalista - tanto na sua vertente anglo-saxã, como entre os autores latinoamericanos - que possui como pilar fundamental para o crescimento econômico e desenvolvimento dos países, a sofisticação da produção e o processo de Mudança Estrutural em direção aos setores de maior produtividade e de maiores externalidades sociais e tecnológicas (Clark, 1957; Lewis, 1954; Prebisch, 1949).

\subsection{Principais causas da desindustrialização}

São cinco as principais causas da desindustrialização abordadas neste estudo: i) a relação inversa entre emprego e a produtividade; ii) a alteração de preços relativos entre a indústria e serviços; iii) a globalização; iv) a ilusão estatística e v) a Doença Holandesa.

\subsubsection{Relação inversa entre emprego e a produtividade}

Nesta situação, o crescimento da produtividade da indústria é superior ao de serviços e a demanda por empregos cresce numa velocidade inversamente proporcional à produtividade, atraindo mais trabalhadores para o setor de serviços do que para a manufatura. Isso ocorre porque a elasticidade da demanda por mão de obra do setor secundário é menor do que a elasticidade da demanda do setor terciário (Rowthorn; Wells, 1987).

Esta primeira causa possui impacto na redução da mão de obra do setor industrial, entretanto, não tem impacto no valor adicionado da manufatura. Assim, o indicador que capta a desindustrialização nesta ocasião é a relação entre o emprego industrial e o nível geral de emprego da economia. 
Há desindustrialização no Brasil? Um estudo da abordagem clássica e de análises alternativas entre 1998 e 2014

\subsubsection{Alteração de preços relativos entre indústria e serviços}

A elevação da produtividade industrial vis-à-vis a de serviços gera uma alteração nos preços relativos, diminuindo o preço dos produtos industriais em relação aos serviços. Desse modo, a produção industrial pode se elevar e, ao mesmo tempo, a indústria perder participação na economia devido a uma mudança de preços relativos que prejudique a indústria em comparação com os demais setores (Baumol, 1967; Kollmeyer, 2009).

Para Iverson e Cusack (2000), a partir de determinado crescimento da renda, a demanda por serviços se torna maior, diminuindo a participação dos bens industriais. A representação gráfica desse fenômeno é um U invertido, no qual a demanda relativa por manufatura primeiro se eleva com o crescimento da renda, todavia, regride conforme a renda alcança patamares maiores. Neste caso, a desindustrialização pode ser medida pela queda da participação do valor adicionado da indústria de transformação como porcentagem do PIB.

Segundo Krugman e Lawrence (1993) o preço das mercadorias caiu em comparação ao de serviços, devido à elevação da produtividade na manufatura ter sido repassada como menores preços aos consumidores.

\subsubsection{Globalização}

Outra causa da desindustrialização foi atribuída à globalização, o que Rowthorn e Wells (1987) denominaram de "trade-related de-industrialization". Publicações como Wood (1995) e Saeger (1997) defendem que o declínio da participação da mão de obra nos países centrais foi, em grande medida, gerado pela ampliação do comércio norte-sul, o que promoveu um deslocamento da produção para países com menor custo do fator trabalho (Global Sourcing).

Alderson (1999) compartilha esse entendimento e aponta o crescente comércio entre os Estados Unidos com os países do Sul, assim, como os fluxos de Investimento Direto Externo em direção a esses países, como elemento central para a desindustrialização americana.

Although direct investment is not the sole cause of deindustrialization, it is 'certainly a major reason that the United States lost a significant fraction of its manu-facturing base' (Harrison; Bluestone 1988, p. 29).

Todavia, não só os países avançados sentem os reflexos da globalização na sua estrutura produtiva; a crescente globalização e a expansão das cadeias globais de valor têm alterado as cadeias de produção que se encontram menos integradas territorialmente devido ao que Nolan (2001) denominou de "big business revolution", no qual as empresas passaram a se concentrar mais em seu "core business", ampliando os seus gastos em P\&D, os gastos em Tecnologia da Informação (TI) e em publicidade, além de fusões e aquisições em nível internacional. 
Esse movimento tem estimulado grandes fluxos de Investimentos Diretos Externos em direção a países do leste e sudeste asiático, especialmente a China, o que, em parte, responde pelo processo de desindustrialização, não apenas dos países já desenvolvidos, mas também nos em desenvolvimento, sobretudo da América Latina e da África. No Brasil, segundo Maia (2018), o atrofiamento de diversos setores têxteis é decorrente do aprofundamento da globalização e do acirramento da competição internacional.

No entanto, Rowthorn e Ramaswamy (1999), demonstram que a desindustrialização dos países avançados ocorreu principalmente por fatores internos, como a mudança na relação entre a elasticidade-renda da demanda por produtos manufaturados e o de serviços, sendo que os fatores externos, como o comércio norte-sul, possuem pouca relevância para explicar o fenômeno da desindustrialização dos países centrais. Krugman e Lawrence (1993) defendem que as causas da desindustrialização americana são motivadas por fatores internos, sendo o baixo crescimento da produtividade dos serviços a principal razão.

Brady e Denniston (2006) argumentam que a globalização não é a principal causa da desindustrialização, porque apesar de ser um processo em expansão, a globalização ainda é pequena quando comparada com o tamanho do mercado de países como os Estados Unidos e o Japão. Ademais, defendem que a relação entre globalização e desindustrialização pode ser espúria.

\subsubsection{Ilusão estatística: terceirização de serviços industriais}

Neste caso, uma participação do emprego antes alocada na indústria foi realocada na forma de terceirização de serviços, como limpeza, segurança, etc. (Palma, 2014).

No caso brasileiro, a primeira possibilidade de ilusão estatística é que, após a abertura econômica, as empresas industriais nacionais sofreram concorrência direta de produtos importados e, para tornarem-se competitivas, realizaram uma reestruturação organizacional, terceirizando atividades não essenciais ao negócio (Torres; Silva, 2015).

Serviços ligados à manufatura, com destaque para design, pesquisa, propaganda, engenharia e comercialização, são fundamentais em países industrializados. Muitos países desenvolvidos, como os Estados Unidos, apesar de estarem se desindustrializando, mantêm muitos empregos em serviços industriais, compensando parte do declínio de sua produção manufatureira. Nos países do leste asiático que crescem aceleradamente, os serviços industriais também crescem consideravelmente (Unctad, 2016).

Embora os países desenvolvidos tenham se inserido nas cadeias globais de valor, ampliando as exportações de serviços de alto valor e produtividade, a mesma inserção não têm sido a tônica dos países da América Latina, que concentram a sua penetração nas cadeias globais de valor, especialmente, nos bens primários (Unctad, 2016). 
Há desindustrialização no Brasil? Um estudo da abordagem clássica e de análises alternativas entre 1998 e 2014

\subsubsection{Doença Holandesa}

Uma causa importante referente ao processo de desindustrialização foi formulada por Corden e Neary (1982) ao relatar a diminuição dos empregos industriais holandeses devido à ampliação das importações de bens manufaturados como consequência da apreciação da taxa real de câmbio decorrente de um aumento extraordinário nas exportações de gás natural na década de 1960. Após essa publicação se cunhou o termo "doença holandesa" para a apreciação real da taxa de câmbio resultante de uma grande elevação nas exportações de commodities.

O mecanismo de transmissão desta "doença"10 pode ser explicado da seguinte forma: a taxa de câmbio apreciada pelo boom de commodities eleva as importações de bens tradables e, como consequência, promove uma substituição da matriz produtiva do país, gerando uma diminuição da participação dos produtos industrializados - ou pelo menos de maior intensidade tecnológica - em direção a uma especialização em commodities (Corden; Neary, 1982).

Outro argumento para a manifestação da doença holandesa, apresentado pela Unctad (2017, p. 27) é a realocação dos fatores de produção em direção às commodities, em especial, o capital e o trabalho.

As the Dutch disease argument goes, the discovery of natural resources, as well as commodity price booms, may cause the manufacturing industry to shrink because: i) Incentives to reallocate productive resources such as capital and labor to primary sectors lead to a rise in the production of commodities and divert resources away from manufacturing; and ii) An inflow of revenue leads to an exchange rate appreciation, making other economic activities, including manufacturing, less competitive.

No entanto, segundo alguns autores, o significado de doença holandesa incorporou, com o passar do tempo, todos os efeitos negativos macroeconômicos relacionados ao "Mal dos Recursos Naturais" e posteriormente, toda e qualquer desindustrialização excessiva (Palma, 2014). Segundo Ocampo (2002, p. 49): "doença holandesa" deve ser entendida como o "excesso de desindustrialização".

Em seu conceito ampliado por Palma (2014) a doença holandesa ocorreu por três fatores diferentes: 1) A descoberta de recursos naturais, como no caso clássico holandês; 2) O desenvolvimento de export-service activities, como o turismo e o setor financeiro, exemplos que se enquadram nesse aspecto são a Grécia e Hong Kong; e 3) Mudanças no modelo de desenvolvimento econômico, sendo o Brasil um grande destaque devido à alteração de sua política macroeconômica voltada para a substituição de importações para um modelo liberalizante baseado nas premissas do Consenso de Washington (Palma, 2014; Felipe, Mehta e Rhee, 2015; Shafaeddin, 2005; Tregenna, 2016).

(10)“Para Bresser-Pereira (2010), a doença holandesa é uma falha de mercado que possibilita ao país atingir um equilíbrio em conta corrente, mesmo com uma taxa de câmbio sobreapreciada” (Marconi; Rocha, 2012, p. 862). 


\subsubsection{Sobrevalorização cambial}

A sobrevalorização cambial por longo período de tempo é um fator que contribui para a desindustrialização, pois torna os bens comercializáveis internacionais mais competitivos no mercado doméstico e encarece os produtos nacionais no mercado externo. É importante destacar que o impacto do câmbio na estrutura produtiva não é imediato, uma vez que a taxa de câmbio brasileira é bastante volátil, enquanto que a estrutura produtiva é rígida no curto prazo. Dessa forma, há uma histerese que marca essa relação, mas se a tendência ou sinalização de sobreapreciação da moeda permanecer por longo período, os agentes econômicos são desestimulados a investir na expansão da produção local enquanto os produtos importados ganham market share.

O principal motivo para a valorização excessiva e por longo tempo da moeda é o padrão de desenvolvimento adotado. Muitos países, especialmente os países em desenvolvimento da América Latina, alteraram o seu padrão de desenvolvimento e suas instituições de modo a se aproximarem da institucionalidade dos países desenvolvidos e das premissas do Consenso de Washington, estimulando a abertura comercial e impondo como única meta do Banco Central a estabilidade do nível de preços (Palma, 2014; Felipe; Mehta; Rhee, 2015; Shafaeddin, 2005; Tregenna, 2016).

Como o processo de valorização da moeda local beneficia o controle da inflação, a administração da taxa de juros se tornou mais flexível em sua elevação e mais resiliente na sua queda, o que prejudica o setor industrial de duas formas: o câmbio tende a ser mais valorizado e a taxa de juros se torna mais elevada (Marconi; Rocha, 2010; Nassif et al., 2017).

\subsection{Síntese das definições e causas da desindustrialização}

Para sumarizar este referencial teórico sobre desindustrialização - antes de discutir sua hipótese e implicação no Brasil - foi elaborado o Quadro 1, que elenca os diferentes conceitos de desindustrialização (Negativa, Positiva, Prematura, a Visão de Cambridge e a de Mudança Estrutural com especialização regressiva) com suas possíveis causas, ou seja: a relação inversa entre o emprego e a produtividade, a alteração de preços relativos entre indústria e serviços, a globalização, a ilusão estatística, a doença holandesa e a sobrevalorização cambial. 
Quadro 1

Síntese das definições e causas da desindustrialização

\begin{tabular}{|c|c|c|c|c|c|c|c|}
\hline & $\begin{array}{c}\text { Definições de } \\
\text { desindustrialização/ } \\
\text { Causas }\end{array}$ & $\begin{array}{c}\text { Relação } \\
\text { inversa entre } \\
\text { emprego e a } \\
\text { produtividade }\end{array}$ & $\begin{array}{c}\text { Alteração de } \\
\text { preços relativos } \\
\text { entre indústria e } \\
\text { serviços }\end{array}$ & Globalização & $\begin{array}{c}\text { Ilusão } \\
\text { Estatística }\end{array}$ & $\begin{array}{c}\text { Doença } \\
\text { holandesa }\end{array}$ & $\begin{array}{c}\text { Sobrevalorização } \\
\text { Cambial }\end{array}$ \\
\hline \multirow{2}{*}{ Clássica } & Negativa & & $\mathbf{x}$ & $x$ & $\mathbf{x}$ & $\mathbf{x}$ & $\mathbf{x}$ \\
\hline & Positiva & $\mathbf{x}$ & $x$ & & $x$ & & \\
\hline \multirow{3}{*}{$\begin{array}{l}\text { Conceitos } \\
\text { alternativos }\end{array}$} & Prematura & & $\mathbf{x}$ & $x$ & $x$ & $x$ & $x$ \\
\hline & Visão de Cambridge & & & $x$ & & $x$ & $x$ \\
\hline & $\begin{array}{c}\text { Mudança Estrutural } \\
\text { com especialização } \\
\text { regressiva }\end{array}$ & & & $\mathbf{X}$ & $\mathbf{X}$ & $\mathbf{X}$ & $\mathbf{X}$ \\
\hline
\end{tabular}

Fonte: Elaboração própria. 


\subsection{O debate acadêmico sobre a desindustrialização no Brasil}

A desindustrialização do Brasil tem ganhado espaço no debate acadêmico com o aprofundamento da crise econômica de 2008. Este argumento é defendido por Radaelli e Galetti (2014) e por Schymura e Pinheiro (2013) que argumentam que se antes a desindustrialização era uma preocupação estruturalista, passou para o primeiro plano de debate em 2010.

No entanto, a discussão em torno da desindustrialização no Brasil é antiga e possui como pontos centrais a crise econômica da década de 1980 e a abertura econômica e financeira dos anos 1990 (Carneiro, 2002; Ricupero, 2005; Almeida; Feijó; Carvalho, 2005).

Nos anos 2000, a discussão em torno da possível ocorrência de doença holandesa sobre a indústria brasileira ganhou força. $\mathrm{O}$ boom de commodities possibilitou um crescimento médio de aproximadamente 19\% ao ano para as exportações brasileiras entre 2002 e 2008, segundo dados da Unctad $^{11}$, o que permitiu uma sobrevalorização cambial do Real ${ }^{12}$, uma vez que diminuiu a pressão na balança comercial. De acordo com Bacha (2013), houve doença holandesa no Brasil associada à valorização cambial, à melhora dos termos de troca e ao aumento das transferências de recursos financeiros do exterior.

Marconi (2015) aprofunda o tema sobre a desindustrialização precoce no Brasil a partir de uma ótica kaldoriana ${ }^{13}$ ao apontar que a regressão da estrutura industrial parece estar contribuindo para reduzir as taxas de crescimento do PIB, pois implica na redução da taxa de crescimento da produtividade média, do salário e da demanda agregada.

Bonelli e Pessôa (2010) defendem que apesar da indústria ter perdido participação relativa no PIB, esse processo foi condizente a um movimento mundial de perda de participação da indústria. Asseveram que o Brasil estava "sobreindustrializado" nos anos 1970 - o que denominaram de "Doença Soviética" - e que a trajetória descendente da participação industrial no produto seria um ajuste à norma mundial, uma correção do peso do setor industrial na economia que estava sobre-elevado em decorrência do modelo de substituição de importações.

Entretanto, Bonelli, Pessoa e Matos (2012) chegam a afirmar que ocorreu doença holandesa de uma forma muito moderada no Brasil e sustentam a tese de que a indústria tinha um peso acima do normal em parte da década de 1970 e 1980 e que, a partir de 1994, o país passou a ter doença holandesa.

Lazzarini et al. (2013, p. 220) discordam dessa interpretação. Para os autores, não parece ter doença holandesa no Brasil, pelo menos até 2010. A patologia, no caso, seria de "Doença brasileira": "instituições fracas, frequente mudança na regulamentação, deficiências crônicas de infraestrutura, estrutura tributária elevada e intrincada, baixos investimentos em

(11) http://unctadstat.unctad.org/.

(12) "Countries that maintain competitive or undervalued currencies tend to experience more growth-enhancing structural change" (McMillan et al., 2014, p. 12).

(13) Ver Kaldor $(1966,1967)$. 
educação, ciência e tecnologia". O argumento central do artigo é que a produção e a exportação brasileira de commodities não representam um prejuízo para o Brasil - uma maldição dos recursos naturais - e, sim, o contrário, um diferencial estratégico importante para a economia brasileira. Argumento este corroborado por Rocha (2015) e Fishlow (2013, p. 42).

As atuais exportações de commodities não são como a dependência histórica do café. Sua origem está na melhoria da eficiência. Poucos países podem se beneficiar de uma base tão diversificada. Talvez Deus seja mesmo brasileiro.

Contudo, não obstante a eficiência em produzir commodities, a especialização da pauta exportadora gera uma reprimarização da economia - uma especialização regressiva -, na qual a indústria se especializa na produção de um pequeno número de produtos e com menor valor agregado $^{14}$ (Cano, 2012; Marconi; Rocha, 2012; Marconi, 2015). Para MacMillan et al. (2014) e Hausmann, Hwang e Rodrik (2006), quanto maior a participação dos recursos naturais nas exportações, menor será o alcance da mudança estrutural de melhoria de produtividade ${ }^{15}$.

Ishikawa (1992) defende que a maior utilização de insumos importados engendraria ganhos para a produção manufatureira. Na mesma linha de raciocínio, Hummels, Ishii e Yi (2001) argumentam que a utilização de insumos importados para produzir bens exportáveis desenvolve cadeias de comércio e leva as economias a se especializarem em determinados estágios do processo de produção de um bem, inserindo-se nas cadeias globais de valor, ampliando suas exportações e o leque de produtos que ofertam (apud Marconi; Rocha, 2015).

Contudo, o coeficiente de penetração das importações na indústria de transformação cresceu $13,2^{16}$ pontos percentuais entre 2003 e 2013, saindo de 10,5\% em 2003 para 23,7\% em 2013 (Lacerda e Da Rocha Loures, 2015) sem gerar o benefício previsto por Hummels, Ishii e Yi (2001) (Marconi; Rocha, 2012).

A desindustrialização 'made in Brasil' decorre não de um movimento virtuoso de transformação qualitativa da indústria para áreas mais sofisticadas, mas de um processo de desmobilização de elos da cadeia produtiva local, substituída por importações crescentes (Lacerda; Da Rocha Loures, 2015, p. 160).

Outro ponto importante é destacado por Marconi e Rocha (2012, p. 882); “a hipótese de que um processo similar ao das maquillas aconteça no país no longo prazo e seja mais relevante que o efeito positivo, para a produção manufatureira, decorrente da especialização vertical na produção de bens exportáveis". Essa análise é próxima à de Morceiro (2012), que também observa indícios de que setores da indústria de transformação estão se transformando em "maquilas", importando os componentes e apenas montando o bem final.

(14) "The countries that manage to pull out of poverty and get richer are those that are able to diversify away from agriculture and other traditional products" (McMillan; Rodrik, 2011, p. 1).

(15) "Os produtos manufaturados representam $70 \%$ do comércio dos 25 principais países no comércio mundial” (Laplane; Sarti, 2014, p. 337)

(16) Segundo Lacerda e Da Rocha Loures (2014), ocorreu um aumento em todos os setores, com destaque para os de maior valor adicionado. 
Drach (2015) realiza uma investigação da desindustrialização no Brasil entre 2003 e 2013 por meio de uma análise de decomposição estrutural ${ }^{17}$ usando matrizes insumo-produto para explicar as variações do emprego industrial. Suas conclusões reforçam que há indícios do processo de formação de "maquillas" e de desindustrialização. O autor afirma que "observa uma perda de dinamismo da indústria de transformação - perdas relativas de eficiência produtiva - associada a uma ascensão dos setores ligados à base de recursos naturais" (Drach, 2015, p. 79). Já para Hiratuka e Sarti (2017, p. 18):

$\mathrm{O}$ peso dos bens intermediários na estrutura produtiva atesta que a indústria brasileira ainda está longe de ser caracterizada como uma indústria de montagem ("maquilas"), que tende a concentrar suas atividades na produção de bens finais, a partir das importações de componentes, insumos e partes e peças. Mas a tendência em curso é preocupante porque vai nessa direção.

Arbache (2015) complementa a discussão sobre a desindustrialização focando sua análise no setor de serviços e nas suas relações com a manufatura. Segundo o autor, a indústria está cada vez mais consumindo serviços e a elevação da competitividade do setor de serviços será determinante para a retomada do dinamismo industrial brasileiro. Por esse motivo, recomenda a construção de políticas públicas e privadas que incentive a competição no setor terciário, de modo a contribuir para o desenvolvimento da indústria e da economia.

\section{Metodologia}

Para investigar a possibilidade de desindustrialização no Brasil e compreender a polêmica em torno desse debatido assunto, como demonstrado no item anterior, este artigo irá analisar a evolução e as transformações da indústria de transformação brasileira segundo a definição clássica formulada por Rowthorn e Wells (1987), assim como por três conceitos alternativos: i) a desindustrialização prematura; ii) a "visão de Cambridge" e iii) a Mudança Estrutural no interior da indústria de transformação.

\subsection{Fonte de dados}

Para analisar o processo de desindustrialização segundo a abordagem clássica, no período de 1998 a $2014^{18}$, foram utilizados dados da Pesquisa da Indústria Anual (PIAEmpresa, completo) do Instituto Brasileiro de Estatística Econômica (IBGE) para empresas com 30 ou mais funcionários, com o objetivo de contabilizar o crescimento da indústria em termos de Pessoal Ocupado (PO) e de Valor da Transformação Industrial (VTI). Além disso, foram utilizados dados da Relação Anual de Informações Sociais (RAIS) para comparar a evolução do emprego na manufatura com o emprego nas demais atividades econômicas.

(17) Outros estudos, como Nassif, Teixeira e Rocha (2015), Leite (2014) e Neves (2013) também realizaram o método de decomposição estrutural via matrizes de insumo-produto de modo a analisar e debater o processo de desindustrialização no país no período recente.

(18) O período selecionado para a análise dos dados empíricos - de 1998 a 2014 - foi adotado por ser recente e propício para investigação e coleta de dados. 
Também foram utilizados dados das Contas Nacionais (IBGE) para verificar a evolução da participação do Valor Adicionado (VA) da indústria de transformação no PIB brasileiro.

Já a análise da desindustrialização brasileira a partir das concepções alternativas sobre o processo de desindustrialização é realizada, especialmente, a partir da revisão da literatura sobre cada um dos conceitos. No caso da "visão de Cambridge", possui destaque uma análise do saldo comercial do Brasil entre 1998 e 2014 da indústria de transformação brasileira a partir de dados da Organização das Nações Unidas para Desenvolvimento e Comércio (Unctad).

Já para analisar a Mudança Estrutural da indústria de transformação brasileira a fim de verificar a hipótese de especialização regressiva da manufatura, foi realizado o método de shiftshare - que será detalhado no item 2.2 - e foram utilizados dados da Pesquisa Industrial Anual (PIA Empresa) do Instituto Brasileiro de Geografia e Estatística (IBGE), na categoria mais desagregada possível (quatro dígitos) da Classificação Nacional de Atividade Econômica (CNAE). Ou seja, em Classe CNAE. Os dados coletados foram deflacionados pelo Índice de Preços por Atacado - Disponibilidade Interna (IPA-DI ${ }^{19}$ ) da Fundação Getúlio Vargas (FGV) desagregados setorialmente. O objetivo de deflacionar os dados de forma setorial foi avaliar de forma mais precisa o crescimento da produção física e diminuir distorções provenientes das alterações de preços relativos. Foram, então, considerados 200 setores da indústria de transformação conforme o modelo exposto em Maia (2018).

Os 200 setores utilizados neste trabalho representam 95,6\% de todo Pessoal Ocupado na indústria de transformação, em 2014, ou seja, carregam quase a totalidade do universo de informações disponíveis. Com relação ao VTI, representam 82\% do total no ano de 2014. No entanto, excluindo a Classe "Fabricação de produtos do refino de petróleo ${ }^{20 "}$ que representa $15 \%$ do VTI da indústria de transformação, em 2014, os setores utilizados correspondem a 97\% do total.

\subsection{O modelo de shift-share}

O método de shift-share (Fagerberg, 2000), equação 1, analisa se o crescimento da produtividade agregada (somatório entre os $\mathrm{n}$ setores i) é decorrente de alterações na composição setorial da produção ou se é motivada por um crescimento da produtividade do trabalho (Arend et al., 2016), sendo pertinente para investigar a hipótese da manufatura estar se especializando em setores de menor produtividade.

(19) Esse indicador faz parte da base de dados "FGV Dados Premium" e foram cedidos pela instituição para fins acadêmicos.

(20) A maior carência da pesquisa se refere à Classe de "Fabricação de produtos do refino de petróleo" que foi excluída propositalmente por dois motivos: i) devido à alocação da PIA Empresa para firmas com mais de 30 empregados em "Setor principal", ou seja, toda a atividade de empresas que produzem em mais de um setor são classificadas inteiramente no seu setor preponderante e como o "Setor principal" da Petrobras é o "Refino de Petróleo", todo o Valor Adicionado na extração de petróleo pela Petrobras é também alocado como Refino; ii) possui um elevado VTI, o que distorce e prejudica algumas análises relativas. 


$$
\begin{aligned}
& \frac{\Delta \mathrm{P}=\sum_{i=1}^{n} P_{i b}\left(S_{i f}-S_{i b}\right)+\sum_{i=1}^{n}\left(P_{i f}-P_{i b}\right)\left(S_{i f}-S_{i b}\right)+\sum_{i=1}^{n}\left(P_{i f}-P_{i b}\right) S_{i b}}{P_{i b}} \\
& \mathrm{P}=\text { produtividade do trabalho; } \mathrm{b}=\text { ano base (1998); } \mathrm{f}=\text { ano final (2014); } \\
& \mathrm{S}=\text { participação do } \mathrm{PO} \text { da indústria no total de empregos. }
\end{aligned}
$$

Embora o modelo shift-share evidenciado seja dividido em três partes, neste estudo nos concentraremos apenas na sua primeira, ou seja, o "efeito deslocamento estático" (Peneder, 2002, p. 8), que analisa se está ocorrendo uma Mudança Estrutural da produtividade intrasetorialmente. Será analisado se os setores mais produtivos - de maior produtividade ( $\left(\mathrm{VTI}_{\mathrm{i}} / \mathrm{PO}_{\mathrm{i}}\right)$ em 1998 - ganharam participação no período de 1998 a 2014, o que é verificado se $\sum_{i=1}^{n} P_{i b}\left(S_{i f}-S_{i b}\right)>0$. Caso contrário, se o valor for negativo, isso significa uma realocação dos setores em direção aos setores de menor produtividade.

\section{Análise da desindustrialização no Brasil}

\subsection{A evolução da indústria brasileira entre 1998 e 2014. Estaria o Brasil desindustrializando sob a ótica clássica?}

Quando se analisa o crescimento do emprego na indústria de transformação, segundo os dados do Relatório Anual de Informações Sociais (RAIS) fornecidos pelo Ministério do Trabalho, percebe-se que houve um crescimento médio de 3,8\% ao ano e de $82,5 \%$ no total do período. Em 1998, trabalhavam 4,4 milhões de trabalhadores na indústria de transformação e, em 2014, esse valor passou para 8,1 milhões (Tabela 1). Como parte desse crescimento é reflexo da formalização dos trabalhadores, não houve, necessariamente, o crescimento de $3,8 \%$ ao ano de Pessoal Ocupado (PO) nesse setor e, sim, um aumento do número de trabalhadores com carteira assinada dessa magnitude (Medeiros, 2015).

Tabela 1

Crescimento do emprego por atividade econômica (Brasil, 1998-2014)

\begin{tabular}{l|r|r|r|r|}
\hline \multicolumn{1}{|c|}{ Atividade } & \multicolumn{1}{|c|}{$\mathbf{1 9 9 8}$} & $\mathbf{2 0 1 4}$ & $\begin{array}{c}\text { Crescimento } \\
\text { Médio a.a }\end{array}$ & $\begin{array}{c}\text { Crescimento } \\
\text { acumulado }\end{array}$ \\
\hline Extrativa Mineral & 104.956 & 257.606 & $5,8 \%$ & $145,4 \%$ \\
\hline Indústria de transformação & 4.476 .993 & 8.171 .022 & $3,8 \%$ & $82,5 \%$ \\
\hline Construção Civil & 1.136 .900 & 2.815 .686 & $5,8 \%$ & $147,7 \%$ \\
\hline Serviços & 11.898 .985 & 27.491 .700 & $5,4 \%$ & $131,0 \%$ \\
\hline Administração Pública & 5.853 .457 & 9.355 .833 & $3,0 \%$ & $59,8 \%$ \\
\hline Agricultura & 1.012 .012 & 1.479 .663 & $2,4 \%$ & $46,2 \%$ \\
\hline Total & $\mathbf{2 4 . 4 8 3 . 3 0 3}$ & $\mathbf{4 9 . 5 7 1 . 5 1 0}$ & $\mathbf{4 , 5 \%}$ & $\mathbf{1 0 2 , 5 \%}$ \\
\hline
\end{tabular}

Fonte: Elaboração própria a partir de RAIS.

Apesar do crescimento do PO da indústria de transformação (3,8\% ao ano) ter sido superior ao crescimento do pessoal ocupado na administração pública $(3,0 \%)$ ou na agricultura $(2,4 \%)$, este foi inferior ao da indústria extrativa $(5,8 \%)$, ao da construção civil, aos serviços 
$(5,8 \%)$ e ao total da economia $(4,5 \%)$. Com isso, a participação da manufatura caiu no total de empregos formais do país de 18,2\%, em 1998, para 16,4\%, em 2014. Já o setor de serviços cresceu 6 pontos percentuais e passou a representar 55\% dos empregos registrados no Brasil em 2014 (Tabela 2).

Por outro lado, analisando os dados da PIA Empresa ${ }^{21}$ para firmas com 30 ou mais empregados que, ao contrário da RAIS, contabiliza os trabalhadores não formais, observa-se um crescimento do PO de 3,4\% ao ano no interregno de 1998 a 2014. Segundo essa estatística, em 1998, havia 3,8 milhões de empregados na indústria de transformação e, em 2014, 6,6 milhões.

Já o VTI da indústria de transformação brasileira teve um crescimento médio real deflacionado pelo IPA da indústria de transformação no período - de 2,48\% ao ano. Em preços correntes correspondia a R $\$ 159$ bilhões, em 1998, e passou para R 934 bilhões, em 2014, como mostra a Tabela 2.

Tabela 2

VTI (R \$ bilhões) da indústria de transformação (1998-2014)

\begin{tabular}{c|c|c}
\hline Ano & $\begin{array}{c}\text { VTI - preços } \\
\text { correntes }\end{array}$ & $\begin{array}{c}\text { VTI - preços } \\
\text { constantes de 1998 }\end{array}$ \\
\hline 1998 & 159 & 159 \\
\hline 2001 & 266 & 169 \\
\hline 2004 & 442 & 168 \\
\hline 2008 & 642 & 203 \\
\hline 2011 & 783 & 231 \\
\hline 2014 & 934 & 236 \\
\hline Crescimento médio (a.a.) & $11,7 \%$ & $2,5 \%$ \\
\hline
\end{tabular}

Fonte: Elaboração própria a partir da PIA Empresa.

Já o Produto Interno Bruto (PIB) cresceu à taxa média de 3,2\% ao ano e 64,3\% no acumulado do período (Banco Central, 2016). Com isso, a participação do valor adicionado da manufatura no PIB - medido como a razão do Valor da Transformação Industrial (VTI) sobre o PIB - caiu, porque sua taxa de crescimento foi inferior ao crescimento do Produto.

A participação do valor adicionado da indústria de transformação no PIB entre 1998 e 2014, a partir dos dados das Contas Nacionais disponibilizadas pelo IBGE, revela uma desindustrialização no Brasil, uma vez que a participação da indústria de transformação alcançou o seu maior patamar em 2004. Contudo, sofreu uma severa queda em 2009, devido à crise mundial de 2008 e não se recuperou desde então. Em 2014 sua participação foi de 10,8\% do PIB, 2,6 pontos percentuais menos do que em 1998, como mostra o Gráfico 1 a seguir.

(21) PIA-Empresa, tabela Completa/Empresa. 
Gráfico 1

Participação do VA da indústria de transformação no PIB

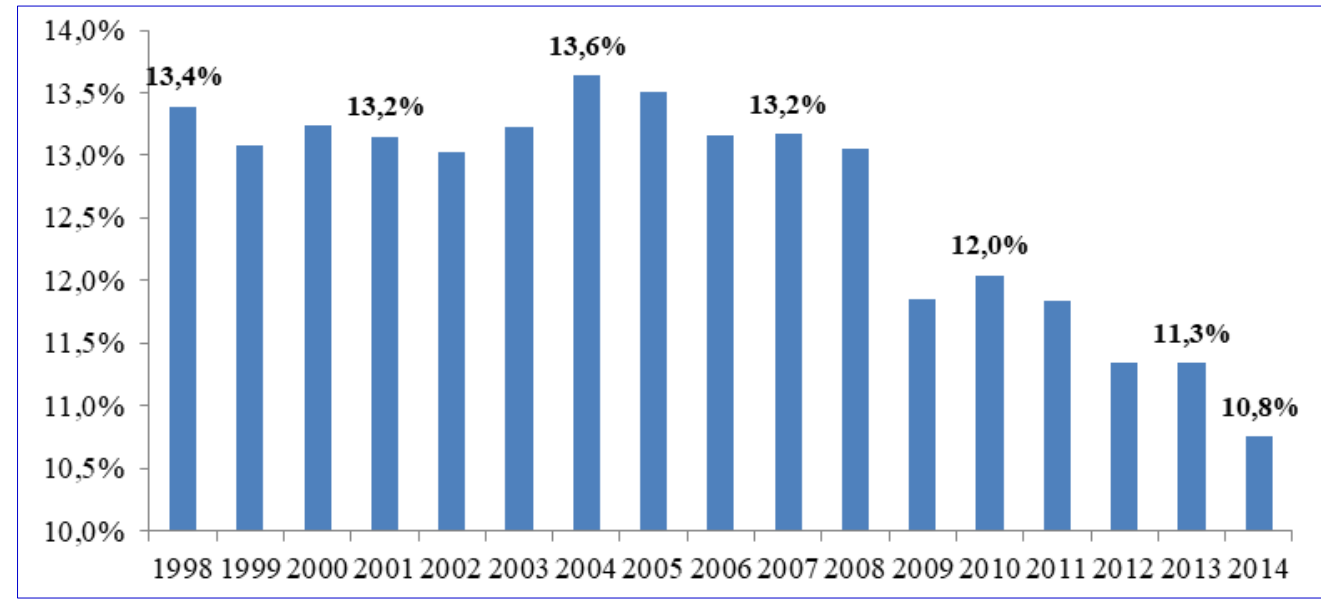

Fonte: Elaboração própria a partir das Contas Nacionais (IBGE).

O número de empresas com 30 ou mais funcionários da indústria de transformação cresceu em média 3,1\% ao ano entre 1998 e 2014, abrindo aproximadamente 14,5 mil novas firmas ao longo desses 17 anos.

O crescimento do VTI $(2,5 \%)$ da indústria de transformação, deflacionado pelo IPADI, foi inferior ao crescimento do PO $(3,4 \%)$, de modo que a produtividade da indústria de transformação, medida como a razão VTI/PO, caiu no período. Se, em 1998, um trabalhador médio da indústria de transformação gerava $R \$ 41,7$ mil, passou a produzir $R \$ 35,8$ mil em 2014 - em preços de 1998 -, o que representa um crescimento negativo de $0,9 \%$ ao ano (PIA/IBGE), como evidencia a Tabela 3. Esse dado é preocupante, porque quanto menor a produtividade de um país, menor sua competitividade, os salários e a sua renda.

Tabela 3

Número de empresas, PO e Produtividade (R \$PO) - Brasil 1998-2014

\begin{tabular}{c|c|c|c}
\hline Ano & Empresas & PO & Produtividade** $^{*}$ \\
\hline 1998 & 23.443 & 3.819 .409 & 41.674 \\
\hline 2001 & 26.346 & 4.187 .836 & 40.417 \\
\hline 2004 & 30.396 & 4.968 .228 & 33.896 \\
\hline 2008 & 34.554 & 5.764 .319 & 35.152 \\
\hline 2011 & 38.295 & 6.446 .107 & 35.846 \\
\hline 2014 & 38.118 & 6.566 .525 & 35.865 \\
\hline $\begin{array}{c}\text { Crescimento médio } \\
\text { a.a. }\end{array}$ & $\mathbf{3 , 1 \%}$ & $\mathbf{3 , 4 \%}$ & $\mathbf{- 0 , 9 \%}$ \\
\hline
\end{tabular}

Fonte: Elaboração própria a partir da PIA Empresa e de IBGE.

* Empresas com 30 ou mais funcionários

**Calculada como a relação VTI/PO sendo o VTI deflacionado pelo IPA da indústria de transformações a preços de 1998. 
Em suma, os dados de participação relativa do emprego industrial e do valor adicionado da manufatura demonstrados neste item evidenciam que o Brasil apresentou entre 1998 e 2014 um processo de desindustrialização, uma vez que a participação da indústria de transformação é declinante em ambos os indicadores. Contudo, como a variação absoluta do pessoal ocupado (3,4\% a.a.) e do Valor da Transformação Industrial (2,5\% a.a.) possuíram taxas de crescimento positivas, não está correto definir a desindustrialização brasileira como uma desindustrialização negativa na acepção clássica formulada por Rowthorn e Wells (1987), mas tampouco como positiva.

Os resultados encontrados convergem com a literatura econômica especializada recente. Segundo Torres e Silva (2015), a maioria das publicações que abordaram o tema da desindustrialização no Brasil utilizaram valores relativos para analisar a evolução da participação da indústria de manufatura, como, por exemplo: Coutinho (1997), Carneiro (2008), Bresser-Pereira (2009), Oreiro e Feijó (2010). Esses autores demonstraram uma preocupação com relação à desindustrialização no Brasil.

Todavia, os artigos que focaram sua pesquisa em investigar o desenvolvimento da indústria em termos absolutos, seja via produção ou exportação de produtos industriais, não constataram, ou não são tão pessimistas com relação à desindustrialização no país, uma vez que a produção e a exportação de manufaturados se expandiram em valores absolutos. Trabalhos de referência nesta abordagem são: Nassif (2008), Puga (2007) e Barros e Pereira (2008) (apud Torres e Silva, 2015).

Para Soares et al. (2010, p. 17),

A literatura recente tem sido pouco conclusiva sobre uma desindustrialização no caso brasileiro, bem como acerca das suas principais causas. Entretanto, foi possível verificar que não há uma desindustrialização absoluta no Brasil, ambos os níveis de produto e emprego têm aumentado. Há uma perda relativa no produto e emprego.

Entretanto, existem na literatura internacional diferentes formas de refletir, medir e analisar a questão da desindustrialização, que denominamos como conceitos alternativos, pois são diferentes da visão convencional sobre o tema, marcada pela célebre pesquisa de Rowthorn e Wells (1987). Dado que a análise clássica sobre o assunto tem sido pouco conclusiva sobre o assunto no Brasil, a utilização de outros conceitos para analisar e diagnosticar com maior profundidade a questão da desindustrialização brasileira se faz necessária.

\subsection{Análise dos conceitos alternativos sobre a desindustrialização no Brasil}

Os três conceitos alternativos sobre desindustrialização que foram identificados anteriormente são: i) Desindustrialização prematura; ii) A visão de Cambridge e iii) A mudança estrutural com especialização regressiva. Esses conceitos foram definidos como alternativos, porque se diferem da análise clássica formulada por Rowthorn e Wells (1987), que se tornou a 
bibliografia de referência no assunto. Entretanto, apesar de tais abordagens serem descritas como alternativas, considera-se que elas são também complementares para analisar o fenômeno da desindustrialização de modo aprofundado.

\subsubsection{Desindustrialização prematura - evidências para o Brasil}

A América Latina possui evidências de desindustrialização prematura. Esse pelo menos é o diagnóstico de Shafaeddin (2005), Dasgupta e Singh (2006) ${ }^{22}$, Palma (2014) e Rodrik (2016). Para os autores mencionados, as políticas adotadas de liberalização econômica das décadas de 1980 e 1990 estimularam uma desindustrialização precoce dos países da Região. Segundo Palma (2014, p. 17), "Brazil and the three Southern Cone countries experienced the greatest de-industrialisation following their economic reforms".

O declínio da indústria na América Latina é particularmente agudo no Brasil, uma vez que até meados da década de 1970 o valor adicionado da manufatura brasileira era equivalente ao da China, Índia, Coréia, Malásia e Tailândia somados. Contudo, em 2008 equivalia a menos de 10\% (Palma, 2011).

Palma (2011; 2014) argumenta que o Brasil e a América Latina, de modo geral, possuem uma desindustrialização prematura devido à adoção de políticas macro-econômicas que estimularam a substituição do superávit comercial em manufaturados, por políticas que promoveram a especialização em produtos e setores no qual o país possui vantagens comparativas $^{23}$.

O Gráfico 2, a seguir, evidencia que o Brasil perdeu acentuada participação do valor adicionado da indústria de transformação no PIB antes de alcançar um PIB per capita compatível com os países desenvolvidos quando esses iniciaram o seu processo de desindustrialização.

Observa-se que a queda da participação da indústria no PIB, na grande maioria dos países, ocorre de maneira gradual conforme os países se tornam mais ricos. Contudo, a trajetória do Brasil destoa no gráfico, por ser quase vertical, ou seja, a redução da participação da indústria de transformação ocorreu antes da contrapartida elevação da renda per capita, configurando-se como um caso de prematura desindustrialização; enquanto nos países desenvolvidos esse processo tem início com uma renda per capita de aproximadamente US\$ 20.000, no Brasil a renda per capita não alcançava a marca de US\$10.000 (Fiesp, 2013).

(22) "Latin American deindustrialization exhibits all the signs of industrial failure" (Dasgupta; Singh, 2006, p. 19).

(23) "Policies that sought to generate a trade surplus in manufacturing have been substituted by policies that promote specialization based on comparative advantages and, hence, in accordance with countries' resource endowments. This has led to fast premature deindustrialization" (Unctad, 2017, p. 38). 
Gráfico 2

Participação da Indústria de Transformação x Evolução da Renda per capita países selecionados (1970-2010)

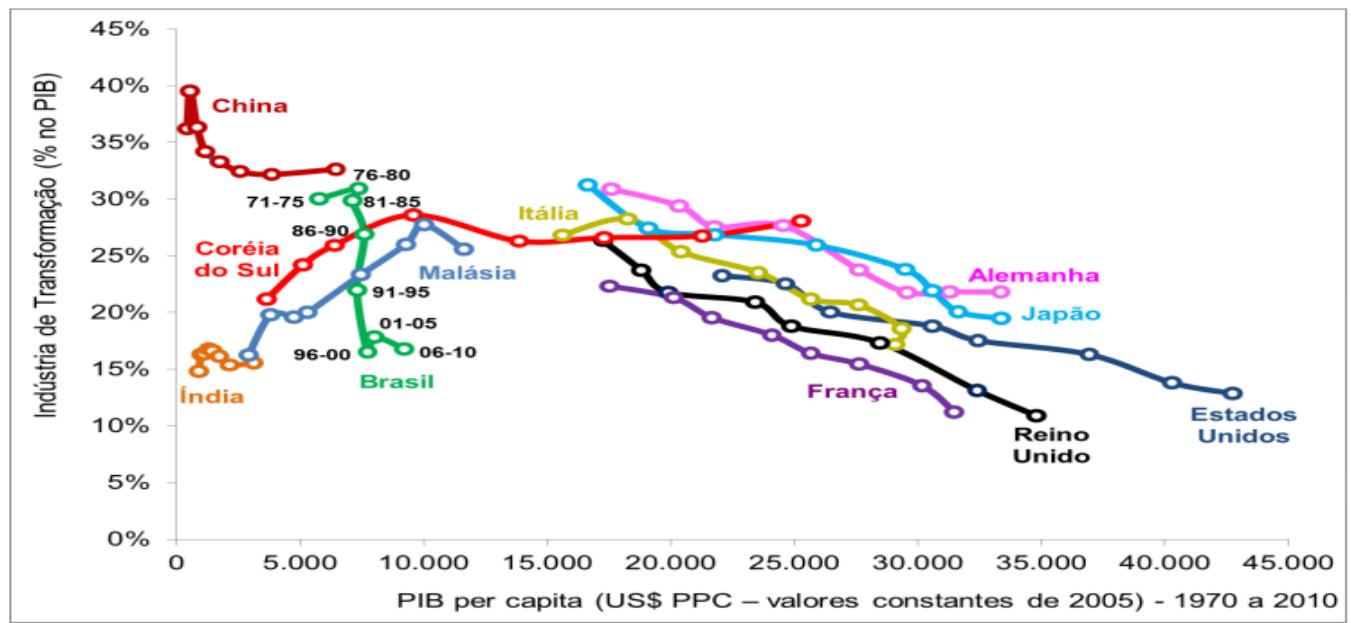

Fonte: FIESP (2013).

\subsubsection{A visão de Cambridge e o déficit comercial da indústria de transformação}

Como exposto no item 1.2.2, a desindustrialização segundo a visão de Cambridge seria o resultado de déficits comerciais gerados pela indústria de transformação. Em sintonia com esse argumento, Bresser-Perreira (2008, p. 14) indica que "não é a participação das exportações de manufaturados no total de exportações, mas a participação do saldo comercial de manufaturados que é relevante para avaliar a existência ou não de doença holandesa". O argumento do autor é que o Brasil pode ampliar suas exportações de manufaturados, mas simultaneamente estar se desindustrializando, uma vez que sustente déficits comerciais nesse setor.

Para Cypher (2016), grande parte do atual debate em torno da desindustrialização no Brasil é centrada no comércio internacional e na hipótese de doença holandesa, uma vez que as exportações de bens primários cresceram de forma acelerada, simultaneamente com a valorização cambial do Real, nos anos 2000.

Pela análise do Gráfico 3, a seguir, é patente a deterioração do saldo comercial da manufatura brasileira após 2007. Não obstante o Brasil tenha gerado um superávit comercial entre 2003 e 2007, observa-se uma drástica reversão em 2008 - já apresentando déficits de US\$ 40 bilhões no setor manufatureiro - que se acentua nos anos seguintes e ultrapassam os US\$ 80 bilhões nos anos de 2013 e 2014. 
Gráfico 3

Evolução do saldo comercial e da manufatura - Brasil (1998-2014) US\$ bilhões

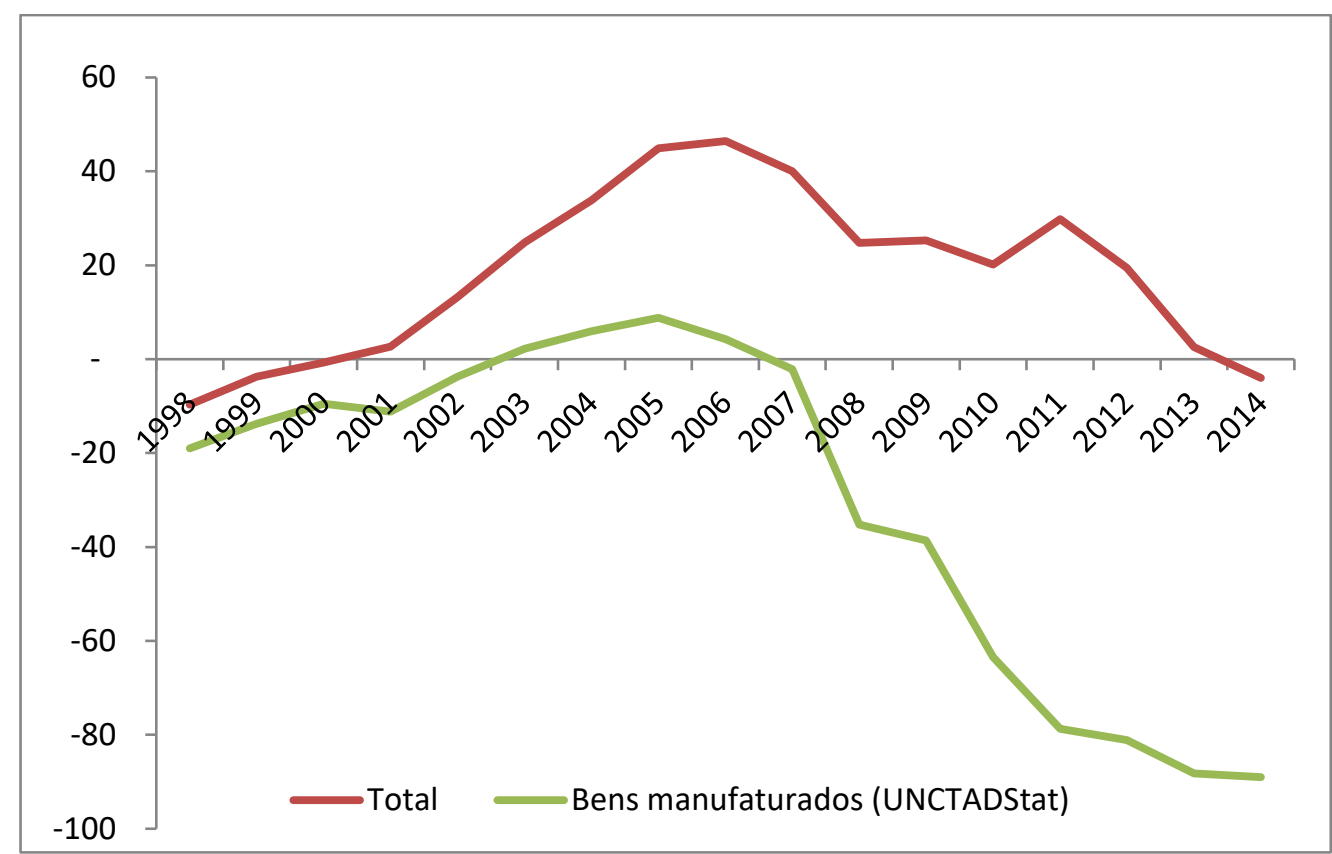

Fonte: Elaboração própria a partir da UnctadStat.

Os expressivos valores apresentados desde 2008 e a trajetória do déficit comercial da manufatura são evidências de uma desindustrialização patológica segundo a abordagem de Cambridge, além de onerar significativamente a balança de pagamento brasileira.

São três as principais causas desse processo de ampliação dos déficits dos produtos manufaturados. Os dois primeiros já foram discutidos na seção anterior: a doença holandesa e a sobrevalorização cambial. O terceiro, por sua vez, se deve à globalização e ao acirramento da competição internacional (Laplane, 2015; Coutinho; Kupfer, 2015; Hiratuka; Sarti, 2017).

Hiratuka e Sarti (2017) enfatizam que o contexto internacional é marcado por um aprofundamento da competição internacional e a reorganização das empresas transnacionais. De acordo com Coutinho e Kupfer (2015), após a crise de 2008, deteriorou-se a participação da indústria de transformação e erodiu-se a competitividade em manufaturas, resultando em déficits comerciais crescentes dessa categoria, levantando preocupações a respeito da sustentabilidade de longo prazo do balanço de pagamentos.

A perda de dinamismo industrial vai se tornar clara a partir de 2011 e tem a ver com a contração, seguida de lento crescimento do comércio internacional de manufaturas, com grande acirramento da concorrência mundial. A esse contexto desfavorável se somará uma significativa erosão da competitividade do setor manufatureiro brasileiro em relação a seus concorrentes. Em consequência, a despeito da continuada expansão da demanda doméstica por manufaturas, a produção doméstica estagnou, dando lugar a uma crescente penetração de importações, inclusive de bens finais. (Coutinho; Kupfer, 2015, p. 169). 
Há desindustrialização no Brasil? Um estudo da abordagem clássica e de análises alternativas entre 1998 e 2014

Para Laplane (2015) as transformações no mercado internacional de manufatura passam na década de 2000 e 2010 por uma grande queda de preços provocada pela engrenagem sino-asiática de produção - baseada em baixos salários, ampliação da escala de produção com elevação do progresso técnico - que tem estimulado as empresas transnacionais sediadas no Brasil a migrar a expansão de capacidade em suas filiais sediadas na Ásia, ou em seus países de origem, realizando apenas investimentos para preservar a rentabilidade do capital já enraizado no país.

\subsubsection{Mudança estrutural - a desindustrialização negativa brasileira}

O desenvolvimento econômico de um país passa por mudanças da sua estrutura produtiva e, consequentemente, alterações na sua produtividade. O processo de Mudança Estrutural pode gerar ganhos agregados de produtividade quando o crescimento dos setores mais produtivos supera as taxas de crescimento dos setores menos produtivos, o chamado Bônus Estrutural do crescimento, ampliando a parcela dos trabalhadores em setores mais produtivos, de maior formalização e de melhor remuneração (Jacinto; Ribeiro, 2013; Unctad, 2016).

Diversos autores, dentre eles Vries et al. (2015), McMillan et al. (2014) Timmer et al. (2014) e Diao et al. (2017), evidenciam que tanto a América Latina e a África passam por um processo de Mudança Estrutural com especialização em setores de menor produtividade, ou seja, os trabalhadores têm migrado dos setores mais produtivos para os de menor produtividade. Os países asiáticos, por outro lado, ampliam a participação nos setores de maior produtividade, apresentando Bônus Estrutural do crescimento.

A ferramenta utilizada por esses autores foi o método de shift-share que decompõe a produtividade em diferentes efeitos, incluindo o da composição intra-setorial, ou seja, que analisa as alterações na produtividade agregada advindas do intercâmbio dos trabalhadores entre os diferentes setores da economia.

A análise do método de shift-share específica para a indústria de transformação brasileira realizada neste estudo a partir da desagregação da manufatura em 200 setores entre 1998 e 2014 verifica a hipótese de desindustrialização negativa no país conforme a definição de Rasiah (2011), segundo a qual há uma especialização regressiva da estrutura produtiva, pois a produtividade da indústria de transformação brasileira teve uma perda relativa de $\mathrm{R} \$ 450,00$ (a preços de 1996) devido às alterações na estrutura produtiva, uma vez que o "efeito deslocamento estático", teve um valor negativo $-\sum_{i=1}^{n} P_{i b}\left(S_{i f}-S_{i b}\right)=-0,45<0 \quad(\mathrm{R} \$$ mil por trabalhador) - de modo que a alteração da composição da estrutura produtiva da indústria de transformação foi em direção aos setores menos produtivos $\left(\mathrm{VTI}_{\mathrm{i}} / \mathrm{PO}_{\mathrm{i}}\right)$, acarretando uma perda de produtividade de $-1,2 \%$ em termos relativos. Esse resultado contrasta com o crescimento agregado da produtividade que cresceu $10 \%$ em termos relativos e $\mathrm{R} \$ 4.447,00$, em preços de 1996, como demonstra a Tabela 4 a seguir. 
Tabela 4

Crescimento da produtividade total e da mudança estrutural

(efeito deslocamento estático) dos setores da manufatura entre 1998 e 2014

\begin{tabular}{c|c|c}
\hline Efeito & Absoluta (R\$) & Relativa (\%) \\
\hline $\begin{array}{c}\text { Deslocamento } \\
\text { estático }\end{array}$ & -450 & $-1,2$ \\
\hline Total & 4.470 & 12 \\
\hline
\end{tabular}

Fonte: Elaboração própria.

\section{Conclusão}

A maioria das nações se encontra frente a um desafio relacionado à desindustrialização, fenômeno este que está relacionado a diversas causas e que pode ser negativo ou positivo, dependendo da sua intensidade, impacto e origem.

Pela revisão da literatura sobre o assunto, observa-se que o Brasil possuiu ou não desindustrialização de acordo com o período utilizado para análise e com os indicadores adotados, não ocorrendo esse fenômeno de forma tão conclusiva para vários autores. Isso se deve a uma leitura conservadora e clássica a respeito desse fenômeno. Ao analisar a desindustrialização sob diferentes métricas e a partir de conceitos alternativos, a desindustrialização brasileira recebe contornos mais evidentes, uma vez que tem gerado elevados déficits comerciais e está se especializando regressivamente, ou seja, em setores de menor produtividade e conteúdo tecnológico, o que, segundo uma leitura não convencional, são elementos que revelam um processo de desindustrialização negativa no Brasil.

Como a análise realizada neste estudo aponta que os principais motivos para a desindustrialização brasileira no período foram motivados pela doença holandesa, à sobrevalorização cambial por longo período e devido ao acirramento da competição internacional em manufaturados, a manutenção de uma taxa de câmbio competitiva é uma estratégia positiva para reverter ou, pelo menos, retardar o atual movimento de desindustrialização no Brasil. Além disso, a organização de uma estrutura mais focada na exportação de modo a inserir o país em cadeias globais de valor em bens mais sofisticados seria bastante salutar.

Por fim, outros mecanismos para melhorar a competitividade nacional, como simplificação tributária - especialmente se coadunada com maior equidade e redução da carga de impostos indiretos em detrimento da ampliação dos impostos diretos, como dividendos, capital e herança -, melhorar infraestrutura, canais de financiamento produtivo e à inovação, entre tantos outros aspectos para melhor o ambiente de negócios para se empreender no país, compõem uma importante agenda para o país e o seu desenvolvimento industrial, assim como desenvolver elos importantes para fornecer para o agronegócio, como a produção de 
Há desindustrialização no Brasil? Um estudo da abordagem clássica e de análises alternativas entre 1998 e 2014

fertilizantes e máquinas e equipamentos agrícolas, uma vez que a produção brasileira está se expandindo nos setores baseados em recursos naturais.

\section{Bibliografia}

ALMEIDA, J. S. G.; FEIJÓ, C. A.; CARVALHO, P. G. Ocorreu uma desindustrialização no Brasil? São Paulo: IEDI. 2005

ALDERSON, Arthur S. Explaining deindustrialization: globalization, failure, or success? American Sociological Review, p. 701-721, 1999.

ARBACHE, J. Por quê serviços? In: BARBOSA, N et al. (Org.). Indústria e desenvolvimento produtivo no Brasil. Rio de Janeiro: Editora Elsevier, 2015.

AREND, $\mathrm{M}$ et al. Mudança estrutural redutora da produtividade: o falling behind brasileiro. In: ENCONTRO NACIONAL DE ECONOMIA, 44, Anpec, 2016.

BACHA, E. Bonança externa e desindustrialização: uma análise do período 2005-2011. In: BACHA, E.; DE BOLLE, M. (Org.). O futuro da indústria no Brasil: desindustrialização em debate. Rio de Janeiro: Civilização Brasileira, 2013. p. 97-120.

BAUMOL, W. Macroeconomics of unbalanced growth: the anatomy of urban crisis. American Economic Review, v. 57, Jun. 1967.

BELL, D. The coming of post-industry society. Venture in social forecasting. New York, 1973.

BERRIEL, T.; BONOMO, M.; CARVALHO, C. V. Diversificação da economia e desindustrialização. In: BACHA, E.; DE BOLLE, M. (Org.). O futuro da indústria no Brasil: desindustrialização em debate. Rio de Janeiro: Civilização Brasileira, 2013.

HARRISON, B.; BLUESTONE, B. The deindustrialization of America: plant closings, community abandonment, and the dismantling of basic industry. Basic Books, 1982.

BONELLI, R.; PESSÔA, S. Desindustrialização no Brasil: um resumo da evidência. FGV/IBRE, mar. 2010. (Texto para Discussão, n. 7). Disponível em: http://bit.ly/GSoutello3. Acesso em: 15 ago. 2015.

BONELLI, R.; PESSÔA, S. D. A.; MATOS, S. Desindustrialização: novas evidências, velhas dúvidas. In: SEMINÁRIO sobre Desindustrialização. IBRE/FGV, 2012. Disponível em: http://www.iepecdg.com.br.

BRADY, D.; DENNISTON, R. Economic globalization, industrialization and deindustrialization in affluent democracies. Social Forces, p. 297-329, 2006.

BRASIL. Banco Central do Brasil. Banco de dados agregados. Sistema Sisbacen. Disponível em: http://bit.ly/GSoutello9/. Acesso em: 20 set. 2015.

BRASIL. Instituto Brasileiro de Geografia e Estatística. Contas Nacionais. Disponível em: www.ibge.gov.br. Acesso em: jul. 2017. 
BRASIL, Instituto Brasileiro de Geografia e Estatística. Pesquisa Anual da Indústria. Disponível em: www.ibge.gov.br. Acesso em: out. 2016.

BRASIL. Relação Anual de Informações Sociais. Disponível em: http://www.rais.gov.br. Acesso em: nov. 2016.

BRESSER-PEREIRA, L. C. The dutch disease and its neutralization: a Ricardian approach. Brazilian Journal of Political Economy, v. 28, n. 1, p. 47-71, jan./mar. 2008.

BRESSER-PEREIRA, L. Globalização e competição: por que alguns países emergentes têm sucesso e outros não. Elsevier, 2010.

BRESSER-PEREIRA, L; GALA, P. Macroeconomia estruturalista do desenvolvimento. Revista de Economia Política, São Paulo, v. 30, n. 4, 2010.

BRESSER-PEREIRA, L; NASSIF, A; FEIJÓ, C; ARAÚJO, E. Structural change and economic development: is Brazil catching up or falling behind? Cambridge Journal of Economics, v. 39, n. 5, p. 1307-1332, 2015.

CANO, W. A desindustrialização no Brasil. Economia e Sociedade, Campinas, v. 21, p. 831851, dez. 2012.

CARNEIRO, R. Desenvolvimento em crise: a economia Brasileira no último quartel do século XX. Editora Unesp, 2002.

CARRASCO, V.; MELLO, J. M. P. de. Um conflito distributivo esquecido: notas sobre a economia política da desindustrialização. In: BACHA, E.; DE BOLLE, M. (Org.). O futuro da indústria no Brasil: desindustrialização em debate. Rio de Janeiro: Civilização Brasileira, 2013. p. 97-120.

CLARK, C. The conditions of economic progress. London: MacMillan, 1957.

CORDEN, W.; NEARY, J. Peter. Booming sector and de-industrialisation in a small open economy. The Economic Journal, v. 92, n. 368, p. 825-848, 1982.

COUTINHO, L. A especialização regressiva: um balanço do desempenho industrial pósestabilização. In: VELLOSO, João. P. R. (Org.). Brasil: desafios de um país em transformação. Rio de Janeiro: José Olympio, 1997.

COUTINHO, L.; KUPFER, D. As múltiplas oportunidades de desenvolvimento e o futuro da indústria brasileira. In: DEZ anos de política industrial: balanços e perspectivas (2004-2014). Agência Brasileira de Desenvolvimento Industrial, 2015.

CYPHER, J. M. Emerging contradictions of Brazil's neo-developmentalism: precarious growth, redistribution, and deindustrialization. Journal of Economic Issues, v. 49, n. 3, p. 617 648, 2016. 
Há desindustrialização no Brasil? Um estudo da abordagem clássica e de análises alternativas entre 1998 e 2014

DASGUPTA, S.; SINGH, A. Manufacturing, services and premature de-industrialization in developing countries. Cambridge, UK: Centre for Business Research, 2006. p. 1-29. (CBR Working Papers, n. 327).

DIAO, $\mathrm{X}$ et al. The recent growth boom in developing economies: a structural change perspective. National Bureau of Economic Research, 2017.

DRACH, D. Determinantes estruturais do emprego industrial para o período 2003-13: uma abordagem via decomposição estrutural. Dissertação (Mestrado)-Instituto de Economia da Unicamp, Campinas, 2016.

FAGERBERG, J. Technological progress, structural change and productivity growth: a comparative study. Structural Change and Economic Dynamics, v. 11, n. 4, p. 393-411, 2000.

FELIPE, J. et al. Sectoral engines of growth in developing Asia: stylized facts and implications. Malaysian Journal of Economic Studies, v. 46, n. 2, p. 107-133. 2009. Working paper version available at: http://www.adb.org/publications/sectoral-engines-growth-developing-asiastylized-facts-and-implications.

FELIPE, J.; MEHTA, A.; RHEE, C. Manufacturing matters... But it's the jobs that count. Asian Development Bank Economics Working Paper Series, n. 420, 2015.

FISHLOW, A. Origens e consequências da substituição de importações: 40 anos depois. In: BACHA, E.; DE BOLLE, M. (Org.). O futuro da indústria no Brasil: desindustrialização em debate. Rio de Janeiro: Civilização Brasileira, 2013. p. 97-120.

FUCHS, R. The service economy. New York: National Bureau of Economic Research, distributed by Columbia University Press, 1968.

FUNDAÇÃO GETÚLIO VARGAS. Instituto Brasileiro de Economia: Índice de Preços por Atacado - Setorial, FGV Dados Premium.

GHANI, E.; O'CONELL, S. Can service be a growth escalator in low income countries? Washington, DC: World Bank, 2014. (Policy Research Working Paper, n. 6971). Available at: http://documents.worldbank.org/curated/en/2014/07/19877603/can-service-growth-escalatorlow-income-countries-can-servicegrowth-escalator-low-income-countries.

HAUSMANN, R., HWANG, J.; RODRIK, D. What you export matters. Journal of Economic Growth, 12, p. 1-25, 2007.

HIRATUKA, C.; SARTI, F. Transformações na estrutura produtiva global, desindustrialização e desenvolvimento industrial no Brasil. Brazilian Journal of Political Economy/Revista de Economia Politica, v. 37, n. 1, 2017.

HIRSCHMAN, A. The strategy of economic development. New Heaven: Yale University Press, 1958. 
Bento Antunes de Andrade Maia

HUMMELS, D.; ISHII J.; YI, K. The nature and growth of vertical specialization in world trade. Journal of International Economics, v. 54, n. 1, p. 75-96, 2001.

ISHIKAWA, J. Trade patterns and gains from trade with an intermediate good produced under increasing returns to scale. Journal of International Economics, 32: p. 57-81, 1992.

IVERSEN, T.; CUSACK, T. The causes of welfare states expansion: deindustrialization or globalization? World Politics, 52, p. 313-349, 2000.

JACINTO, P.; RIBEIRO, E. Crescimento da produtividade no Brasil no setor de serviços e da indústria: dinâmica e heterogeneidade. ANPEC/BNDES, 2013.

KALDOR, N. Causes of the slow rate of economic growth of the United Kingdom. Cambridge: Cambridge University Press, 1966.

KALDOR, N. Strategic factors in economic development. Ithaca, NY: New York State School of Industrial and Labour Relations, Cornell University, 1967.

KIM, C.; LEE, S. Different paths of deindustrialization: Latin American and Southeast Asian countries from a comparative perspective. Journal of International and Area Studies, p. 65-81, 2014.

KOLLMEYER, C. Explaining deindustrialization: how affluence, productivity growth, and globalization diminish manufacturing employment. American Journal of Sociology, v. 114, n. 6, p. 1644-1674, 2009.

KRÜGER, J. Productivity and structural change: a review of the literature. Journal of Economic Surveys, v. 22, n. 2, p. 330-363, 2008.

KRUGMAN, P.; LAWRENCE, R. Trade, jobs and wages. NBER, 1993. (WP, n. 4478).

LACERDA, C., DA ROCHA LOURES. Para o Brasil evitar o risco da desindustrialização. In: BARBOSA, N. et al. (Org). Indústria e desenvolvimento produtivo no Brasil. Rio de Janeiro: Editora Elsevier, 2015.

LAPLANE, M.; SARTI, F. Prometeu acorrentado: o Brasil na indústria mundial no início do século XXI, 2014.

LAPLANE, M. A indústria ainda é o motor do crescimento? Teoria e evidencias. In: DEZ anos de política industrial: Balanços e perspectivas (2004-2014). Agência Brasileira de Desenvolvimento Industrial, 2015.

LAZZARINI, S. et al. Commodities no Brasil: maldição ou benção. In: O FUTURO da indústria no Brasil: desindustrialização em debate. Rio de Janeiro: Civilização Brasileira, 2013. p. $97-120$.

LEWIS, W. Arthur. Economic development with unlimited supplies of labour. The Manchester School, v. 22, n. 2, p. 139-191, 1954. 
Há desindustrialização no Brasil? Um estudo da abordagem clássica e de análises alternativas entre 1998 e 2014

MAIA, B. Mudança estrutural na indústria de transformação brasileira entre 1998 e 2014. Tese (Doutorado)-IE. Unicamp, Campinas, 2018.

MARCONI, N.; ROCHA, M. Taxa de câmbio, comércio exterior e desindustrialização precoce-o caso brasileiro. Economia e Sociedade, v. 21, n. 4, p. 853-888, 2015.

MARCONI, N. Estrutura produtiva e desenvolvimento econômico. In: BARBOSA, N et al. (Org.). Indústria e desenvolvimento produtivo no Brasil. Rio de Janeiro: Editora Elsevier, 2015.

MARQUETTI, A. Progresso técnico, distribuição e crescimento na economia brasileira: 1955-1998. Estudos Econômicos, v. 32, n. 1, 2002.

MCMILLAN, M. et al. Globalization, structural change, and productivity growth, with an update on Africa. World Development, v. 63, n. 1, p. 11-32, 2014.

MEDEIROS, C. Inserção Externa, crescimento e padrões de consumo na economia brasileira. [s.n.t.].

MORCEIRO, P. Desindustrialização na economia brasileira no período 2000-2011: abordagens e indicadores. Dissertação (Mestrado)-Universidade Estadual Paulista, Faculdade de Ciências e Letras, Araraquara, 2012.

NASSIF, A. Há evidências de uma desindustrialização no Brasil? Revista de Economia Política, v. 28, n.1 (109), p. 71-96, jan./mar. 2008.

NASSIF, A.; BRESSER-PEREIRA, L.; FEIJO, C. The case for reindustrialisation in developing countries: towards the connection between the macroeconomic regime and the industrial policy in Brazil. Cambridge Journal of Economics, p. bex028, 2017.

NOLAN, P. China and the global economy. Basingstoke: Palgrave, 2001.

OCAMPO, J.; CEPAL, N. U. Globalização e desenvolvimento. 2002.

OCAMPO, J. Macroeconomy for development: countercyclical policies and production sector transformation. Revista CEPAL, n. 104, Aug. 2011.

OREIRO, J; FEIJÓ, C. Desindustrialização: conceituação, causas, efeitos e o caso brasileiro. Revista de Economia Política, v. 30, n. 2, p. 219-232, 2010.

PALMA, J. De-industrialisation,'premature'de-industrialisation and the dutch-disease. Revista NECAT-Revista do Núcleo de Estudos de Economia Catarinense, v. 3, n. 5, p. 7-23, 2014.

PALMA, J. G. Quatro fontes de "desindustrialização" e um novo conceito de "doença holandesa. In: CONFERÊNCIA DE INDUSTRIALIZAÇÃO, DESINDUSTRIALIZAÇÃO E DESENVOLVIMENTO, São Paulo: Fiesp, Iedi, 2005.

PALMA, J. G. Why has productivity growth stagnated in most Latin-American countries since the neo-liberal reforms? 2011. 
PENEDER, M. Structural change and aggregate growth. Structural Change and Economic Dynamics, v. 14, p. 427-448, 2002.

PREBISCH, R. O desenvolvimento econômico da América Latina e seus principais problemas. Revista Brasileira de Economia, v. 3, n. 3, p. 47-111, 1949.

PUGA, P. Aumento das importações não gerou desindustrialização. Visão do Desenvolvimento, BNDES, Rio de Janeiro, 26, p. 1-8, 2007.

RADAELLI, V.; GALETTI,J. Além da crise global: desafios de uma política industrial para a "reindustrialização". Ipea, 2014. (Radar, n. 31). Disponível em: https://www.ipea.gov.br/portal/images/stories/PDFs/radar/140226_radar31_cap4.pdf

RASIAH, Rajah. Is Malaysia facing negative deindustrialization? Pacific Affairs, v. 84, n. 4, p. 714-735, 2011.

RICUPERO, R. Desindustrialização precoce: futuro ou presente do Brasil? (Sintese das principais teses e demonstrações do relatório Trade and Development Report, 2003). Nova Iorque, Genebra: Unctad, 2005. Disponível em: http:// goo.gl/h57ra0.

ROCHA, C. Recursos naturais e estratégia de desenvolvimento no Brasil. In: BARBOSA, N et al. (Org.). Indústria e desenvolvimento produtivo no Brasil. Rio de Janeiro: Editora Elsevier, 2015.

RODRIK, D. Premature deindustrialization. Journal of Economic Growth, v. 21, n. 1, p. 133, 2016.

RODRIK, D. What's so special about China's exports? China \& World Economy, v. 14, n. 5, p. 1-19, Sept./Oct. 2006.

ROWTHORN, R.; COUTTS, K. De-industrialisation and the balance of payments in advanced economies. Cambridge Journal of Economics, v. 28, n. 5, p. 767-790, 2004.

ROWTHORN, R.; RAMASWAMY, R. Desindustrialization: causes and implications. International Monetary Fund, 1999.

ROWTHORN, R.; WELLS, J. De-industrialization and foreign trade. Cambridge: Cambridge University Press, 1987.

SAEGER, Steven S. Globalization and deindustrialization: myth and reality in the OECD. Review of World Economics, v. 133, n. 4, p. 579-608, 1997.

SARTI, F.; HIRATUKA, C. Desempenho recente da indústria brasileira no contexto de mudanças estruturais domésticas e globais. Campinas: Unicamp. IE, 2017. (Texto para Discussão, n. 290).

SCHYMURA, L.; PINHEIRO, M. Política industrial brasileira: motivações e diretrizes. In: In: BACHA, E.; DE BOLLE, M. (Org.). O futuro da indústria no Brasil: desindustrialização em debate. Rio de Janeiro: Civilização Brasileira, 2013. p. 97-120. 
Há desindustrialização no Brasil? Um estudo da abordagem clássica e de análises alternativas entre 1998 e 2014

SHAFAEDDIN, S. Trade liberalization and economic reform in developing countries: structural change or deindustrialization? Geneva: Unctad, 2005. (Unctad Discussion Papers, n. 179).

SINGH, A. UK industry and the world economy: a case of deindustrialization? Cambridge Journal of Economics, v. 1, n. 2, p. 113-36, 1977.

SOARES, C. et al. Uma abordagem econométrica do processo de desindustrialização no caso brasileiro: elementos para o debate. In: ENCONTRO NACIONAL DE ECONOMIA, 36, Anpec, 2010.

SOUZA, F. Por que a indústria parou. In: BARBOSA, N.; MARCONI, N. (Org.). Indústria e desenvolvimento produtivo. Rio de Janeiro: Editora Elsevier, 2015.

TIMMER, M. et al. Patterns of structural change in developing countries. Groningen Growth and Development Centre, University of Groningen, 2014.

TORRES, R. L.; SILVA, H. C. Uma crítica aos indicadores usuais de desindustrialização no Brasil. In: ENCONTRO NACIONALDE ECONOMIA, 40, 2012, Porto de Galinhas. Anais Eletrônicos... Disponível em: http://www.anpec.org.br/encontro_2012.htm.

TREGENNA, F. Characterising deindustrialisation: an analysis of changes in manufacturing employment and output internationally. Cambridge Journal of Economics, v. 33, p. 433-466, 2009.

TREGENNA, F. Deindustrialisation, structural change and sustainable economic growth. Maastricht: Unido, 2016. (Industrial Development Report).

UNCTAD. Structural transformation and industrial policy. Genebra; New York, 2016.

VRIES, G. et al. Patterns of structural change in developing countries. Groningen Growth and Development Centre, University of Groningen, 2014.

WOOD, A. North-South trade, employment and inequality: changing fortunes in a skill-driven world. Oxford University Press on Demand, 1995. 